\title{
A Cross-sectional Study Examining the Risk Factors Associated with Lymphedema and its Prevalence in Breast Cancer Patients after Level 3 Axillary Lymph Node Dissection
}

\author{
Sibel KIBAR, Meltem DALYAN ARAS, Sibel ÜNSAL DELIALIOĞLU, Belma Füsun KÖSEOĞLU \\ Department of Physical Medicine and Rehabilitation, Ankara Physical Medicine and Rehabilitation Training and Research Hospital, Ankara, Turkey
}

\begin{abstract}
Objective: To determine the prevalance of lymphedema after breast cancer treatment with level 3 axillary lymph node dissection (ALND) and to evaluate the risk factors which underlie this condition.

Material and Methods: A total of 190 women $>18$-years-old who underwent breast cancer treatment with level 3 ALND $>6$ months ago were included in this cross-sectional study. The sociodemographic and clinical characteristics of all of the patients were recorded, and all patients were evaluated for lymphedema of the upper extremity by a circumferential measurement method.

Results: On examination, 79 (41.5\%) women had lymphedema with a mean development time of $12.7 \pm 26.62$ months. After univariate analysis, the patients' age, body mass index (BMI), and number of metastatic lymph nodes (LNs) were found to increase the development of lymphedema. In addition, chemotherapy, breast or chest wall radiotherapy, and axillary radiotherapy also played a role. In the multivariate model, BMI (OR=5.491; $95 \% \mathrm{Cl}: 1.382-21.82)$, metastatic $\mathrm{LNs}(\mathrm{OR}=0.314 ; 95 \% \mathrm{Cl}: 0.118-0.839)$, axillary radiotherapy (OR=15.34; $95 \% \mathrm{Cl}: 5.526-42.581)$, chemotherapy $(\mathrm{OR}=5.325 ; 95 \% \mathrm{Cl}: 1.48-19.153)$, and age $(\mathrm{OR}=1.044 ; 95 \% \mathrm{Cl}: 1.007-1.083)$ were significantly associated with an increased risk of lymphedema. Conclusion: This study demonstrated that there was a higher lymphedema prevalence ratio of $41.5 \%$ in breast cancer patients who underwent level 3 ALND and found that the risk factors for lymphedema development were axillary radiotherapy, chemotherapy, number of metastatic LNs, age, and BMI.
\end{abstract}

Keywords: Breast cancer, lymphedema, prevalence, risk factors

\section{Introduction}

Lymphedema is a chronic and progressive complication which develops secondary to breast cancer treatment $(1,2)$. It is still a common problem despite recent advances in the treatment of breast cancer (3). Lymphedema may develop during breast cancer treatment or it may occur years later. Pain, tightness, heaviness, and skin infections such as recurrent cellulitis may be observed in the arm of affected patients and lymphangiosarcoma can occur in rare cases (4). This treatment complication may affect the social, vocational, and sexual life as well as the physical and emotional status of patients, resulting in a decrease in the quality of life (QOL) (5).

Lymphedema lasting $>3$ months is known as persistent or chronic lymphedema $(3,6)$. In some patients, mild to moderate lymphedema turns into severe lymphedema over a period of 
time (7). Finding a cure becomes almost impossible once the chronic advanced stage is reached. However, strategies for risk management, early diagnosis, and treatment can stop the progression of early lymphedema (3).

The exact mechanism of lymphedema and its risk factors have not yet been defined. It has been reported that the incidence and severity of this condition are well correlated with the extent of surgical dissection $(8,9)$; however, other factors may also play a role because many patients who undergo axillary lymph node dissection (ALND) do not develop lymphedema (8). On the other hand, in recent years, sentinel lymph node dissection (SLND) has decreased the incidence of lymphedema because it allows for the detection of the first metastatic node, thereby limiting the number of ALNs extracted. On the other hand, the addition of adjuvant radiotherapy, particularly axillary radiotherapy, has been shown to increase the incidence of lymphedema (10). Despite the efforts to ensure breast cancer patients undergo conservative surgery and SLND, one-third of patients with breast cancer suffer from an invasive type of cancer; therefore, ALND and complications due to ALND is inevitable for these patients (11).

A few studies have investigated ALND levels as a possible risk factor; however, these have not been sufficiently evaluated in studies that have focused on breast cancer-induced lymphedema. Bevilacqua et al. (12) reported the 5-year cumulative incidence rate of lymphedema in breast cancer patients who underwent ALND was 30.3\%; however, it was $79.5 \%$ for those for underwent level 3 ALND. They also emphasized the importance of the ALND levels as a risk factor for lymphedema. In addition, a new meta-analysis also reported that mastectomies were a risk factor (13). Most of our study population underwent mastectomies and all underwent level 3 ALND; therefore, we investigated an almost homogenous study population in terms of surgical methods.

This study aimed to determine the prevalence of lymphedema in breast cancer patients who underwent level 3 ALND, which is known as the most destructive axillary surgery, and to evaluate the risk factors related to this condition. Predefined risk factors could be helpful in identifying the proper type of postoperative follow-up and for developing the necessary treatment plans. They could also prove to be beneficial for the patients themselves to help them change their daily living activities, which could result in a decrease in the development of lymphedema or perhaps prevent it altogether.

\section{Material and Methods}

\section{Participants}

Between 2008 and 2010, 262 Caucasian women with breast cancer who underwent level III ALND subsequent to a modified radical mastectomy or lumpectomy together with chemotherapy or radiotherapy were evaluated for the development of lymphedema at the General Surgery Outpatient
Clinic of Ankara Oncology Training and Research Hospital Patients $>18$ years of age and those with a minimum post-surgical period of 6 months were included in this cross-sectional study. Eighteen patients decided not to participate in the study, and 54 patients with bilateral breast cancer, regional recurrence, or distant metastasis were excluded. In addition, patients with any systemic disease, which caused edema of the extremities, as well as those with a history of upper extremity fracture or surgery that may affect the evaluation process were also excluded. Hence, a total of 190 patients with unilateral breast cancer met the inclusion criteria and participated in the study.

\section{Data Collection and Measurements}

The sociodemographic characteristics of all of the patients were recorded, and the body mass index (BMI) (W-kg)/ $\mathrm{H}^{2}$ $\mathrm{m}^{2}$ ) was calculated after measuring the weight and height. All of the operations were performed by the same team using the same surgical method. All patients underwent level I, II, and III ALND; pectoralis minor muscle was conserved. In addition, modified radical mastectomy technique was often preferred by the surgical team that we collaborated with in this study. Other treatment methods, including breast-chest wall radiotherapy, axillary radiotherapy (25-28 sessions over a period of 5-7 weeks, 40-60 Gy), adjuvant and neoadjuvant chemotherapy (4-8 courses), and hormone therapy, were also documented via the medical charts of the patients. We also identified other surgical complications, including seroma, surgical wound infections, hematoma, and flap necrosis. In addition, we investigated recurrent upper extremity skin infections as another possible complication. Patients who tested positive for one or more of these infections were regarded as having a postoperative complication. Furthermore, we also recorded the elapsed time until the diagnosis of lymphedema after the operation, number of extracted LNs, and number of existing metastatic LNs.

All patients were evaluated for lymphedema of the upper extremities using a circumferential measurement method $(14,15)$. Measurements were performed at the level of the metacarpophalangeal joint, wrist, $10 \mathrm{~cm}$ distal to the lateral epincondyle, and $15 \mathrm{~cm}$ proximal to the lateral epicondyle with a flexible non-stretch tape. A circumferential difference of $\geq 2 \mathrm{~cm}$ at any of these four points between the affected and non-affected arms was defined as lymphedema $(14,15)$. The patients were also questioned about the time it took for the lymphedema to develop and when they first recognized the differences in size between their right and left hands as well as their upper and lower arms (14). All of the lymphedema patients were evaluated with respect to lymphedema stage (4). Stage 1 presents with pitting edema and is reversible. Stage 2 occurs as the edema progresses and becomes more intense, non-pitting, and irreversible. Stage 3 is characterized by advanced lymphedema. In addition, cartilaginous hardening is observed in conjunction with papillomatous outgrowths and hyperkeratosis of the skin in this stage (4). 
All of the patients were also questioned regarding any potential risk factors that may have predisposed them to lymphedema, such as bad hygiene, poor nutrition, and special hobbies. Bad hygiene was evaluated using three questions related to personal hygiene and cleaning. The patients were asked about their daily handwashing habits (hand care), weekly body washing routine, and the cleanliness of their clothes. Those who answered that they washed their hands, bodies, or clothes at the most once a week were then considered to have poor hygiene.

We also evaluated the patients with respect to poor nutrition during the lymphedema development period. The patients answered questions about their body weight and weight loss in the 6 months before this condition began and about their current body weight at the same time and then we calculated their BMI. The patients were classified as having poor nutrition if they had an unintentional weight loss of $>10 \%$ of their body weight during the previous 6 months or a BMI of $<20$. Furthermore, we asked the patients if they had any hobbies that involved the possible overuse of the hands and arms, such as painting, sewing, playing a musical instrument, or garden work, and recorded their answers. We also questioned them regarding whether they had been informed about the lymphedema before or after the operation.

The study was approved by the Ethics Committee of the Ankara Physical Medicine and Rehabilitation Training and Research Hospital. In addition, all patients signed the study consent form and were instructed about lymphedema, preventive measures, positioning, and skin care via an informational brochure and exercise form. Furthermore, those diagnosed with lymphedema were included in a physical therapy and rehabilitation program.

\section{Statistical Analysis}

The Statistical Package for the Social Sciences (SPSS) version 11.5 for Windows software package (SPSS, Inc., Chicago, Illinois, USA) was used for statistical analysis. Descriptive statistics were expressed as mean, standard deviation, minimum, maximum, and median for continuous variables, while categorical variables were expressed as a percentage. Single variable logistic regression analysis was used to evaluate the effects of the demographic and clinical characteristics on the development of lymphedema. After univariate analysis, variables with a value of $p<0.25$ were entered into the multivariate model (16), and multivariable backward stepwise logistic regression was used to identify the effects of the clinical factors determined to affect lymphedema together with some of the risk factors. For every variable, the odds ratio (OR) and $95 \%$ confidence intervals (Cls) were calculated, and a $p$ value $<0.05$ was considered to be statistically significant.

\section{Results}

\section{Demographic Variables}

The mean age of the 190 patients was $52.31 \pm 10.40$ years

\begin{tabular}{|c|c|c|c|c|}
\hline \multicolumn{2}{|l|}{ Variables } & $\begin{array}{c}\text { Total } \\
(\mathrm{n}=190)\end{array}$ & $\begin{array}{l}\text { Non-LE } \\
(n=111)\end{array}$ & $\begin{array}{c}\mathrm{LE} \\
(\mathrm{n}=79)\end{array}$ \\
\hline \multicolumn{2}{|l|}{ Age } & $52.31 \pm 10.40$ & $50.9 \pm 10.2$ & $54.3 \pm 10.4$ \\
\hline \multicolumn{2}{|l|}{$<40$} & 17 (8.9\%) & $12(10.8 \%)$ & $5(6.3 \%)$ \\
\hline \multicolumn{2}{|l|}{$40-60$} & 135 (71.1\%) & $84(75.7 \%)$ & $51(64.6 \%)$ \\
\hline \multicolumn{2}{|l|}{$>60$} & $38(20.0 \%)$ & $15(13.5 \%)$ & $23(29.1 \%)$ \\
\hline \multicolumn{5}{|c|}{ Educational level } \\
\hline \multicolumn{2}{|l|}{ University } & $13(6.8 \%)$ & $10(9.0 \%)$ & $3(3.8 \%)$ \\
\hline \multicolumn{2}{|l|}{ High school } & $27(14.2 \%)$ & $17(15.3 \%)$ & $10(12.7 \%)$ \\
\hline \multicolumn{2}{|l|}{ Middle school } & $11(5.8 \%)$ & $8(7.2 \%)$ & $3(3.8 \%)$ \\
\hline \multicolumn{2}{|l|}{ Primary school } & $63(33.2 \%)$ & $34(30.6 \%)$ & $29(36.7 \%)$ \\
\hline \multicolumn{2}{|l|}{ Illiterate } & $76(40.0 \%)$ & $42(37.8 \%)$ & $34(43.0 \%)$ \\
\hline \multicolumn{5}{|l|}{ Marital status } \\
\hline \multicolumn{2}{|l|}{ Single/widow } & $22(11.5 \%)$ & $13(11.7 \%)$ & $9(11.4 \%)$ \\
\hline \multicolumn{2}{|l|}{ Married } & 168 (88.4\%) & $98(88.3 \%)$ & $70(88.6 \%)$ \\
\hline \multicolumn{5}{|l|}{ Work status } \\
\hline \multicolumn{2}{|l|}{ Employed } & $17(8.9 \%)$ & $12(10.8 \%)$ & $5(6.3 \%)$ \\
\hline \multicolumn{2}{|l|}{ Unemployed } & $173(91.1 \%)$ & 99 (89.2\%) & $74(93.7 \%)$ \\
\hline \multicolumn{5}{|l|}{ BMI } \\
\hline \multicolumn{2}{|l|}{$\leq 25$} & $24(12.6 \%)$ & $21(18.9 \%)$ & $3(3.8 \%)$ \\
\hline \multicolumn{2}{|l|}{$>25$} & $166(87.3 \%)$ & $90(81.1 \%)$ & $76(93.7 \%)$ \\
\hline \multirow[t]{2}{*}{ Family history } & $(-)$ & $153(80.5 \%)$ & $85(76.6 \%)$ & $68(86.1 \%)$ \\
\hline & $(+)$ & $37(19.5 \%)$ & $26(23.4 \%)$ & $11(13.9 \%)$ \\
\hline \multicolumn{5}{|l|}{ Comorbidity } \\
\hline \multirow[t]{2}{*}{ DM } & $(-)$ & $152(80.0 \%)$ & $91(82.0 \%)$ & $61(77.2 \%)$ \\
\hline & $(+)$ & $38(20.0 \%)$ & $20(18.0 \%)$ & $18(22.8 \%)$ \\
\hline \multirow[t]{2}{*}{$\mathrm{HT}$} & $(-)$ & $25(65.8 \%)$ & $73(65.8 \%)$ & $52(65.8 \%)$ \\
\hline & $(+)$ & $65(34.2 \%)$ & $38(34.2 \%)$ & $27(34.2 \%)$ \\
\hline \multirow[t]{2}{*}{ Other } & $(-)$ & $183(96.3 \%)$ & $106(95.5 \%)$ & $77(97.5 \%)$ \\
\hline & $(+)$ & $7(3.7 \%)$ & $5(4.5 \%)$ & $2(2.5 \%)$ \\
\hline
\end{tabular}

LE: Iymphedema; BMI: body mass index; DM: diabetes mellitus; HT: hypertension

(range: $27-86$ ). A BMI $\leq 25$ was observed in $12.62 \%$ of patients, and $87.3 \%$ had a $\mathrm{BMI}>25$. The demographic characteristics of the patients according to the presence of lymphedema are shown in Table 1.

\section{Prevalence of Lymphedema}

On examination, $79(41.5 \%)$ out of the 190 patients had lymphedema. The mean time period of our evaluation after breast cancer surgery was $51.88 \pm 54.90$ months (range: 6-244), and the mean time for the development of lymphedema after surgery was $12.7 \pm 26.62$ months (range: 1-177).

We determined that 44 of the patients had Stage 1 (55.7\%), 25 had stage $2(31.6 \%)$, and 10 had stage 3 lymphedema $(12.7 \%)$. The distribution is shown in Figure 1. We also investi- 
Table 2. Assessment of demographic variables as risk factors for lymphedema

\begin{tabular}{|c|c|c|c|c|}
\hline Variables & Non-LE $(n=111)$ & $\operatorname{LE}(n=79)$ & $p$ value & OR $(95 \% \mathrm{CI})$ \\
\hline Age & $50.9 \pm 10.2$ & $54.3 \pm 10.4$ & $0.028^{*}$ & $1.033(1.004-1.063)$ \\
\hline$<40$ & $12(10.8 \%)$ & $5(6.3 \%)$ & - & $1.000^{\mathrm{a}}$ \\
\hline$>60$ & $15(13.5 \%)$ & $23(29.1 \%)$ & $0.038^{*}$ & $3.680(1.076-12.583)$ \\
\hline \multicolumn{5}{|l|}{ Education } \\
\hline Middle school & $8(7.2 \%)$ & $3(3.8 \%)$ & 0.813 & $1.250(0.196-7.956)$ \\
\hline Primary school & $34(30.6 \%)$ & $29(36.7 \%)$ & 0.138 & $2.843(0.714-11.324)$ \\
\hline Illiterate & $42(37.8 \%)$ & $34(43.0 \%)$ & 0.155 & $2.698(0.688-10.589)$ \\
\hline \multicolumn{5}{|l|}{ Marital status } \\
\hline Employed & $12(10.8 \%)$ & $5(6.3 \%)$ & - & $1.000^{\mathrm{a}}$ \\
\hline Unemployed & 99 (89.2\%) & $74(93.7 \%)$ & 0.286 & $1.794(0.606-5.314)$ \\
\hline BMI & $29.1 \pm 4.7$ & $31.9 \pm 4.9$ & $<0.001^{*}$ & $1.131(1.058-1.208)$ \\
\hline$\leq 25$ & $21(18.9 \%)$ & $3(3.8 \%)$ & - & $1.000^{\mathrm{a}}$ \\
\hline$>25$ & $90(81.1 \%)$ & $76(96.2 \%)$ & $0.002^{*}$ & $5.911(1.698-20.583)$ \\
\hline Family history (-) & $85(76.6 \%)$ & $68(86.1 \%)$ & - & $1.000^{\mathrm{a}}$ \\
\hline$(+)$ & $26(23.4 \%)$ & $11(13.9 \%)$ & 0.103 & $0.529(0.244-1.146)$ \\
\hline \multicolumn{5}{|l|}{ Comorbidity } \\
\hline & $91(82.0 \%)$ & $61(77.2 \%)$ & - & $1.000^{\mathrm{a}}$ \\
\hline
\end{tabular}

LE: lymphedema; OR: odds ratio; Cl: confidence interval; BMI: body mass index; DM: diabetes mellitus; $\mathrm{HT}$ : hypertension; ${ }^{\text {a: }}$ reference category $\quad{ }^{*} \mathrm{p}<0.05$

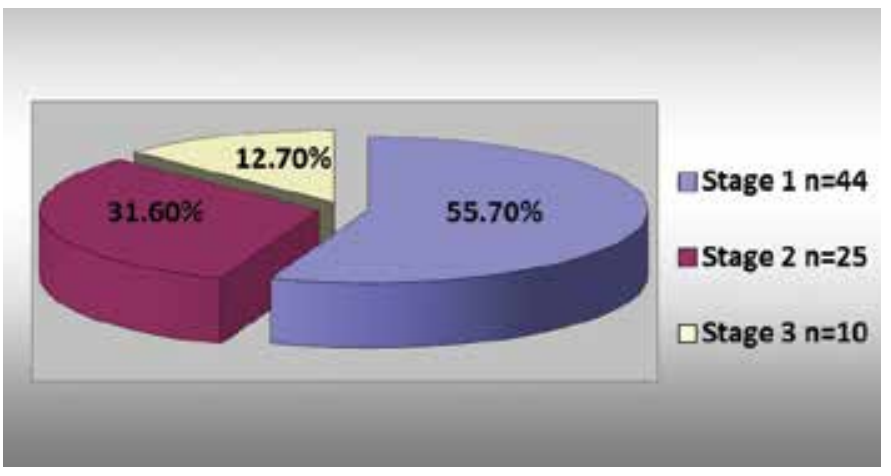

Figure 1. The distribution of the stages of lymphedema

gated the distribution of the lymphedema in the upper extremities and determined that it was located $15 \mathrm{~cm}$ proximal to the elbow in $94.9 \%$ of the patients and $10 \mathrm{~cm}$ distal to the elbow in
$73.4 \%$ of the patients. Furthermore, $25.3 \%$ of the patients had lymphedema on the wrist and $5.6 \%$ at the metacarpophalangial joint level.

\section{Univariate Analysis of Demographic Variables}

After univariate analysis, the patients' ages $(p=0.028, O R=$ $1.033,95 \% \mathrm{Cl}=1.004-1.063)$ and BMIs $(\mathrm{p}<0.001, \mathrm{OR}=1.131$, $95 \% \mathrm{Cls}=1.058-1.208$ ) were found to increase the development of lymphedema, whereas the other sociodemographic variables had no effect. The effects of demographic variables on the development of lymphedema are shown in Table 2.

\section{Univariate Analysis of Clinical Variables}

While 179 patients $(97.21 \%)$ underwent a modified radical mastectomy, only 11 underwent a lumpectomy (5.78\%). We found that neither the surgical method (modified radical mastectomy or lumpectomy) $(p=0.126)$ nor the number of extract- 
Table 3. Assessment of clinical variables as risk factors for lymphedema

\begin{tabular}{|c|c|c|c|c|c|}
\hline Variables & Category & Non-LE $(n=111)$ & LE $(n=79)$ & $p$ value & OR $(95 \% \mathrm{Cl})$ \\
\hline Postoperative Time & & $51.9 \pm 54.9$ & $44.3 \pm 41.6$ & 0.3 & $0.997(0.991-1.003)$ \\
\hline Operated side & Dominant & $45(40.5 \%)$ & $29(36.7 \%)$ & - & $1.000^{\mathrm{a}}$ \\
\hline \multirow[t]{2}{*}{ Surgery } & MRM & $102(91.9 \%)$ & $77(97.5 \%)$ & - & $1.000^{\mathrm{a}}$ \\
\hline & Lumpectomy & $9(8.1 \%)$ & $2(2.5 \%)$ & 0.126 & $0.294(0.062-1.402)$ \\
\hline & $15-25$ & $55(49.5 \%)$ & $39(49.4 \%)$ & 0.607 & $1.210(0.585-2.500)$ \\
\hline & $>25$ & $27(24.3 \%)$ & $23(29.1 \%)$ & 0.37 & $1.453(0.642-3.290)$ \\
\hline Number of metastatic LNs & & $1.8 \pm 4.4$ & $5.2 \pm 7.9$ & $<0.001^{*}$ & $1.115(1.043-1.192)$ \\
\hline Metastatic LNs & - & $60(54.1 \%)$ & $28(35.4 \%)$ & - & $1.000^{\mathrm{a}}$ \\
\hline (Breast-Chest) & + & $51(45.9 \%)$ & $58(73.4 \%)$ & $<0.001^{*}$ & $3.249(1.742-6.060)$ \\
\hline \multirow[t]{2}{*}{ Axillary RT } & - & $94(84.7 \%)$ & $34(43.0 \%)$ & - & $1.000^{\mathrm{a}}$ \\
\hline & + & $17(15.3 \%)$ & $45(57.0 \%)$ & $<0.001^{*}$ & $7.318(3.700-14.475)$ \\
\hline \multicolumn{6}{|l|}{ Chemotherapy } \\
\hline & - & $21(18.9 \%)$ & $4(5.1 \%)$ & - & $1.000^{\mathrm{a}}$ \\
\hline & + & $90(81.1 \%)$ & $75(94.9 \%)$ & $0.005^{*}$ & $4.375(1.439-13.306)$ \\
\hline \multirow[t]{2}{*}{ Hormone Therapy } & - & $39(35.1 \%)$ & $38(48.1 \%)$ & - & $1.000^{\mathrm{a}}$ \\
\hline & + & $72(64.9 \%)$ & $41(51.9 \%)$ & 0.073 & $0.584(0.324-1.53)$ \\
\hline Postoperative complications & - & $88(79.3 \%)$ & $58(73.4 \%)$ & - & $1.000^{\mathrm{a}}$ \\
\hline
\end{tabular}

LE: lymphedema; OR: odds ratio; Cl: confidence interval; MRM: modified radical mastectomy; LNs: lymph nodes; RT: radiotherapy; a: reference category; * $<<0.05$

ed axillary LNs ( $p=0.622)$ were clinical factors that increased the risk for lymphedema. However, the relationship between the number of metastatic LNs and the development of lymphedema was statistically significant $(p<0.001, O R=1.115,95 \%$ $\mathrm{Cl}=1.043-1.192)$. Moreover, adjuvant therapies such as breastchest radiotherapy $(\mathrm{p}<0.001, \mathrm{OR}=3.249,95 \% \mathrm{Cl} s=1.742-$ $6.060)$ and axillary radiotherapy $(\mathrm{p}<0.001, \mathrm{OR}=7.318,95 \%$ $\mathrm{Cl} s=3.700-14.475)$ were observed to increase the development of lymphedema significantly. Of the patients who developed lymphedema, $73.4 \%$ were treated via radiotherapy of the breast or chest wall, and $57 \%$ were treated by additional axillary radiotherapy. Furthermore, $94.9 \%$ of the patients who developed lymphedema underwent chemotherapy, which increased the risk of obtaining this condition $(\mathrm{p}=0.005, \mathrm{OR}=4.375,95 \% \mathrm{Cl}=$ 1.439-13.306). We also determined that only $38 \%$ of the patients with lymphedema were informed about it before or after the operation. Table 3 shows the assessment of clinical variables as risk factors for lymphedema.

\section{Multivariate Analysis of Clinical Variables}

Among the variables $(\mathrm{p}<0.25)$ in the multivariate model, BMI $>25$ ( $\mathrm{p}=0.016$, OR: 5.491, 95\% Cls= 1.382-21.82), metastatic LNs ( $p=0.021$, OR: $0.314,95 \% \mathrm{Cl}=0.118-0.839)$, axillary radiotherapy ( $p<0.001$, OR: 15.340, 95\% Cls=5.526-42.581), chemotherapy ( $p=0.010$, OR: $5.325,95 \% \mathrm{Cl}=1.48-19.153)$, and age $(p=0.020$, OR: $1.044,95 \% \mathrm{Cl}=1.007-1.083)$ were significantly associated with an increased risk of lymphedema. However, we found that having a family history of lymphedema played no part in being afflicted with this condition and neither did any of the associated risk factors. In addition, lumpectomy had no association with lymphedema. Table 4 shows the results of the multivariable backward stepwise logistic regression analysis. 
Table 4. Results of multivariable logistic regression analysis

\begin{tabular}{|c|c|c|c|c|c|}
\hline \multirow[b]{2}{*}{ Models } & \multirow[b]{2}{*}{ Variables } & \multirow[b]{2}{*}{$\begin{array}{l}\text { Odds } \\
\text { Ratio } \\
\end{array}$} & \multirow[b]{2}{*}{$p$} & \multicolumn{2}{|c|}{$95 \% \mathrm{Cl}$} \\
\hline & & & & $\begin{array}{l}\text { Lower } \\
\text { Limit }\end{array}$ & $\begin{array}{c}\text { Upper } \\
\text { Limit }\end{array}$ \\
\hline \multirow[t]{9}{*}{$1^{\text {st }}$} & $\mathrm{BMI}>25$ & 5.695 & 0.015 & 1.394 & 23.26 \\
\hline & Family history & 0.722 & 0.497 & 0.283 & 1.845 \\
\hline & Lumpectomy & 0.546 & 0.225 & 0.206 & 1.45 \\
\hline & Metastatic LNs & 0.322 & 0.024 & 0.12 & 0.863 \\
\hline & Axillary RT & 15.319 & $<0.001$ & 4.797 & 48.922 \\
\hline & RT (Breast-CW) & 0.992 & 0.987 & 0.397 & 2.482 \\
\hline & $\mathrm{CT}$ & 4.926 & 0.019 & 1.293 & 18.764 \\
\hline & Risk Factor & 0.997 & 0.994 & 0.461 & 2.154 \\
\hline & Age & 1.043 & 0.025 & 1.005 & 1.083 \\
\hline \multirow[t]{8}{*}{$2^{\text {nd }}$} & $\mathrm{BMI}>25$ & 5.697 & 0.015 & 1.398 & 23.218 \\
\hline & Family History & 0.723 & 0.493 & 0.286 & 1.827 \\
\hline & Lumpectomy & 0.546 & 0.225 & 0.206 & 1.449 \\
\hline & Metastatic LNs & 0.322 & 0.024 & 0.121 & 0.862 \\
\hline & Axillary RT & 15.314 & $<0.001$ & 4.809 & 48.761 \\
\hline & RT (Breast-CW) & 0.992 & 0.986 & 0.398 & 2.475 \\
\hline & $\mathrm{CT}$ & 4.925 & 0.019 & 1.296 & 18.713 \\
\hline & Age & 1.043 & 0.023 & 1.006 & 1.082 \\
\hline \multirow[t]{7}{*}{$3^{\text {rd }}$} & $\mathrm{BMI}>25$ & 5.693 & 0.015 & 1.399 & 23.16 \\
\hline & Family History & 0.723 & 0.493 & 0.286 & 1.827 \\
\hline & Lumpectomy & 0.546 & 0.221 & 0.207 & 1.438 \\
\hline & Metastatic LNs & 0.322 & 0.024 & 0.121 & 0.862 \\
\hline & Axillary RT & 15.244 & $<0.001$ & 5.43 & 42.8 \\
\hline & $\mathrm{CT}$ & 4.913 & 0.017 & 1.334 & 18.093 \\
\hline & Age & 1.043 & 0.023 & 1.006 & 1.082 \\
\hline \multirow[t]{6}{*}{$4^{\text {th }}$} & $\mathrm{BMI}>25$ & 5.542 & 0.016 & 1.369 & 22.433 \\
\hline & Lumpectomy & 0.538 & 0.203 & 0.207 & 1.398 \\
\hline & Metastatic LNs & 0.319 & 0.022 & 0.119 & 0.851 \\
\hline & Axillary RT & 15.855 & $<0.001$ & 5.668 & 44.352 \\
\hline & $\mathrm{CT}$ & 5.01 & 0.015 & 1.366 & 18.379 \\
\hline & Age & 1.044 & 0.021 & 1.007 & 1.082 \\
\hline \multirow[t]{5}{*}{$5^{\text {th }}$} & $\mathrm{BMI}>25$ & 5.491 & 0.016 & 1.382 & 21.82 \\
\hline & Metastatic LNs & 0.314 & 0.021 & 0.118 & 0.839 \\
\hline & Axillary RT & 15.34 & $<0.001$ & 5.526 & 42.581 \\
\hline & $\mathrm{CT}$ & 5.325 & 0.01 & 1.48 & 19.153 \\
\hline & Age & 1.044 & 0.02 & 1.007 & 1.083 \\
\hline
\end{tabular}

$\mathrm{Cl}$ : confidence interval; BMI: body mass index; LNs: lymph nodes; RT: radiotherapy; CT: chemotherapy; CW: chest wall

\section{Discussion}

The incidence and prevalence of lymphedema has been reported as $0 \%-94 \%$ within various populations $(17,18)$. The main reasons for this broad range are a lack of a standardized definition of this condition, the use of different measurement methods, and varying follow-up periods $(2,19)$. In addition, the average incidence rate was reported as $21.4 \%$ in a recent meta-analysis by DiSipio et al. (13). The high prevalence ratio in our study (41.5\%) was inconsistent with other studies, particularly those in which SLND was performed and those that had low prevalence ratios (3\%-5\%) $(20,21)$. Various authors have also reported a decrease in the postoperative development of lymphedema in conjunction with more conservative surgical techniques as well as limited $\operatorname{ALND}(13,18,20)$. Modified radical mastectomy has also been identified as an important risk factor (13). The reason for our higher ratio may be due to the level 3 ALND that was performed over a wide area along with the mastectomies. Therefore, because our study population consisted solely of breast cancer patients who underwent level 3 ALND, the higher ratio indicated the prevalence of the lymphedema induced by level 3 ALND. In recent years, the number of patients with breast cancer who have undergone SLND has continued to increase. However, ALND is still necessary for some patients who suffer from an invasive type of cancer (11). In our opinion, our data is remarkable for these patients who undergo level 3 ALND.

Previous studies have demonstrated that as the extent of ALND increases, the rate of lymphedema development also increases as a result of more surgical damage to the lymphatic canals $(13,22)$. In our study, we found a significant relationship between the development of lymphedema and the number of metastatic LNs; however, this was not true for the number of extracted LNs. Similarly, other authors found no association between the number of extracted LNs and lymphedema (23).

Postoperative radiotherapy decreases the regional recurrence by three or four times. Therefore, it has an important role in the treatment of breast cancer (24). However, it can also cause lymphedema by obstructing the lymphatic vessels with radiationinduced fibrosis (25). In some studies, radiotherapy of the breast region and axillary radiotherapy were found to be significant risk factors for lymphedema on univariate analysis; however, with multivariate analysis, only axillary radiotherapy was identified as a risk factor $(7,10)$. We found similar results in our study with an increase in lymphedema development after axillary radiotherapy alone.

Chemotherapy has also been determined to be a significant risk factor for the development of lymphedema $(12,23,26,27)$. In a study investigating the cosmetic results of breast cancer treatment, the patient group who underwent adjuvant chemotherapy was determined to have far more complications (26). Similarly, our findings revealed that chemotherapy was a significant risk factor. The exact mechanism is not known; however, one may speculate that those patients receiving chemotherapy may have received more aggressive treatment (27). There are also studies that have reported a lack of association between chemotherapy and lymphedema $(1,23,28)$. These authors argue that although the use of chemotherapy is more frequent in young patients, they experience less lymphedema compared with that in older patients (29). In our study, older patients form the majority of the population that underwent chemotherapy, which may explain why it was a significant risk factor.

Axillary dissection at an advanced age is a significant risk factor for the development of lymphedema $(7,23,29,30)$, and 
advanced age was also found to be a significant risk factor for the development of lymphedema on both univariate and multivariate analyses in our study. This may be explained by the fact that the lymphovenous anastomoses formation occurs more easily at a younger age rather than later in life (31). In contrast, some studies have indicated that advanced age is not a risk factor for the development of lymphedema $(13,28,32)$. A study by Werner et al. (33) explained that these opposing views were because of the more aggressive nature of breast cancer in young women, characterized by the higher incidence of lymphedema associated with intensive cancer treatment, and the vulnerability of young patients to infection and trauma-induced lymphedema because of a more active lifestyle.

Many studies $(2,10,13,15,28,32,34)$ have also reported that $\mathrm{BMI}$ is a significant risk factor for the development of lymphedema, and this study agrees with this conclusion. In a recent study, a significant reduction was observed in arm edema in patients whose body weight and BMI had decreased after a 12-week diet program, and the authors emphasized the importance of weight loss in the treatment of lymphedema (35). In addition, Johansson et al. (36) determined that patients who developed lymphedema were determined to be more inactive, and lymphedema was reported to induce weight gain by limiting daily activities (36). Therefore, patients should be encouraged to return to optimum daily physical activity as quickly as possible after their breast cancer treatment (37). In addition, it should be remembered that obesity may also play a role in causing lymphedema via poor and delayed wound healing due to fat necrosis, secondary infection, regional lymphangitis, and lymphatic obstruction (31). However, some recent reports have surfaced that counteract these conclusions $(6,7)$.

We did not find any relationship between potential risk factors such as bad hygiene, poor nutrition, extremity overuse, and lymphedema. It has been suggested that these factors do not have a direct effect on the development of this condition but that they affect it indirectly by increasing infection and disturbing the healing of the wound (38). Controversy also exists regarding whether recurrent infection is a cause of lymphedema. Lymphedematous tissues are extremely sensitive to infection and even a small open wound can cause lymphatic damage or obstruction by means of a severe infection (23). However, we found that postoperative complications and postoperative recurrent skin infections had no effect on lymphedema.

Systemic diseases, on the other hand, are not thought to play a role in the development of lymphedema (23), and we found nothing to contradict this notion in our study. However, there are some studies that have reported a connection between hypertension and the development of lymphedema (39). Kocak et al. (30) suggested that hypertension should be considered as a factor which increases lymphedema but that it should not be declared as an actual risk factor. It has also been reported that in patients taking antihypertensive drugs, capillary leakage decreases as the arterial pressure decreases, consequently decreasing the rate of lymphedema (40).
It has been reported that lymphedema most commonly develops up to 2 years after surgery for breast cancer (13); however, some authors have suggested that it can take as long as 3-4 years $(32,34)$. Late-onset lymphedema is considered to be mainly due to trauma and infection (34). Brennan et al. (41) determined that one patient developed lymphedema 30 years after a mastectomy and ALND and that this patient's blood glucose had been measured on the affected side a few days prior to the diagnosis. In our study, $81.01 \%$ of the patients developed lymphedema within the first year, and $92.4 \%$ had it within 3 years. In the end, lymphedema may develop within the first month after the operation or even as much as 30 years later. Moreover, the determination of a true incidence rate is also associated with the follow-up period $(2,3,19,30)$. As previously mentioned, the mean time for patient evaluation after breast cancer surgery in our study was 44.3 months. It was also reported that $90 \%$ of the late effects of radiotherapy arise after 3.9 years (42). Therefore, assessments that take place approximately 4 years similar to the evaluation duration of this study would be reasonable. Nonetheless, the effect of the follow-up period on lymphedema development could not be accurately evaluated in this study because of the cross-sectional study design.

In our study, 49 (62.0\%) patients with lymphedema were not informed about lymphedema. Although we did not find a significant relationship between patient education and the development of lymphedema, we believe that in the future, patient education needs more attention because lymphedema mostly develops as a result of infection or trauma. Park et al. (2) reported a higher incidence of lymphedema in patients who were not informed before breast cancer surgery, and preventive self-care activities could prevent the progression of lymphedema. Because lymphedema is not a curable disease, prevention becomes much more important in clinical practice. However, this requires educating patients at the right time.

This study has some limitations. Firstly, we could not use more reliable methods such as perometry to evaluate lymphedema in our study because of technical insufficiencies. We preferred the circumferential measurement technique, which is considered to be the easiest method for application and evaluation (43). The main disadvantage of this method lies in the fact that there may generally be a circumferential difference between dominant and non-dominant extremities. However, this difference generally does not exceed our measurement limit of $2 \mathrm{~cm}$ (20). Although we demonstrated that some risk factors have a negative effect on the development of lymphedema, our cross-sectional design meant that these factors could not be regarded as a precise cause of this condition. In addition, the effect of the follow-up period on lymphedema development also could not be accurately evaluated in this study because of the cross-sectional study design.

\section{Conclusion}

Lymphedema is a disturbing complication which develops secondary to the treatment of breast cancer and affects the patients' QOL. Broad incidence rates have also been reported 
in previous studies, and this has been attributed to different evaluation methods and surgery types. Herein, we evaluated a homogenous patient population in terms of surgical methods and determined that the lymphedema prevalence ratio of the patients who underwent modified radical mastectomy with level 3 ALND was $41.5 \%$. The independent risk factors for lymphedema development in breast cancer patients who underwent level 3 ALND were found to be axillary radiotherapy, chemotherapy, number of metastatic LNs, age, and BMI. It is known that the lymphedema prevalence ratio in breast cancer patients after ALND is higher than those after SLND. In our opinion, physicians treating breast cancer should meticulously diagnose high-risk breast cancer patients who underwent ALND with respect to lymphedema before and after surgery to prevent the development of this condition. Furthermore, these patients should be followed up more rigorously in the post-operative period, and they should be educated, particularly with respect to modifiable risk factors such as obesity.

Ethics Committee Approval: Ethics committee approval was received for this study from the ethics committee of Ankara Physical Medicine and Rehabilitation Training and Research Hospital.

Informed Consent: Written informed consent was obtained from patients who participated in this study.

Peer-review: Externally peer-reviewed.

Author contributions: Concept - M.D.A.; Design M.D.A, S.U.D.; Supervision - M.D.A, S.U.D., B.F.K.; Resource - S.K.; Materials - S.K.; Data Collection and/or Processing - S.K., S.U.D.; Analysis and/or Interpretation - S.K.; Literature Search - S.K.; Writing - S.K., S.U.D., M.D.A.; Critical Reviews - M.D.A, B.F.K.

Acknowledgements: The authors are indebted Dr. Cihangir Özaslan, his coworkers, and all the patients at the Ankara Oncology Training and Research Hospital $4^{\text {th }}$ Surgery Clinic for their contributions to the writing of this article.

Conflict of Interest: No conflict of interest was declared by the authors.

Financial Disclosure: The authors declared that this study has received no financial support.

\section{References}

1. Hinrichs CS, Watroba NL, Rezaishiraz H, Giese W, Hurd T, Fass $\mathrm{KA}$, et al. Lymhedema secondary to postmastectomy radiation: incidence and risk factors. Ann Surg Oncol 2004;11:573-80. [CrossRef]

2. Park JH, Lee $W H$, Chung HS. Incidence and risk factors of breast cancer lymphoedema. J Clin Nurs 2008;17:1450-9. [CrossRef]

3. Hayes SC, Johansson K, Stout NL, Prosnitz R, Armer JM, Gabram S, et al. Upper-body morbidity after breast cancer: incidence and evidence for evaluation, prevention, and management within a prospective surveillance model of care. Cancer 2012;118:2237-49. [CrossRef]

4. Harris SR, Hugi MR, Olivotto IA, Levine M. Steering committee for clinical practice guidelines for the care and treatment of breast cancer. Clinical practice guidelines for the care and treatment of breast cancer: II. Lymphedema. CMAJ 2001;164:191-9.

5. Kwan W, Jackson J, Weir LM, Dingee C, McGregor G, Olivotto IA. Chronic arm morbidity after curative breast cancer treatment: pre- valence and impact on quality of life. J Clin Oncol 2002;20:4242-8. [CrossRef]

6. Hayes SC, Janda M, Cornish B, Newman B. Lymphedema following breast cancer. J Clin Oncol 2009;27:2890. [CrossRef]

7. Bar Ad V, Dutta PR, Solin LJ, Hwang WT, Tan KS, Both S, et al. Timecourse of arm lymphedema and potential risk factors for progression of lymphedema after breast conservation treatment for early stage breast cancer. Breast J 2012;18:219-25. [CrossRef]

8. Bennett Britton TM, Purushotham AD. Understanding Breast Cancer-Related Lymphoedema. Surgeon 2009;7:120-4. [CrossRef]

9. Lawenda BD, Mondry TE, Johnstone PA. Lymphedema: a primer on the identification and management of a chronic condition in oncologic treatment. CA Cancer J Clin 2009;59:8-24. [CrossRef]

10. Warren LE, Miller CL, Horick N, Skolny MN, Jammallo LS, Sadek BT, et al. The impact of radiation therapy on the risk of lymphedema after treatment for breast cancer: a prospective cohort study. Int J Radiat Oncol Biol Phys 2014;88:565-71. [CrossRef]

11. Bevilacqua JL, Kattan MW, Fey JV, Cody HS 3rd, Borgen PI, Van Zee KJ. Doctor, what are my chances of having a positive sentinel node? A validated normogram for risk estimation. J Clin Oncol 2007;25:3670-9. [CrossRef]

12. Bevilacqua JL, Kattan MW, Changhong Y, Koifman S, Mattos IE, Koifman RJ, et al. Nomograms for predicting the risk of arm lymphedema after axillary dissection in breast cancer. Ann Surg Oncol 2012;19:2580-9. [CrossRef]

13. DiSipio $T$, Rye $S$, Newman B, Hayes $S$. Incidence of unilateral arm lymphoedema after breast cancer: a systematic review and metaanalysis. Lancet Oncol 2013;14:500-15. [CrossRef]

14. Norman SA, Miller LT, Erikson HB, Norman MF, McCorkle R. Development and validation of a telephone questionnaire to characterize lymphedema in women treated for breast cancer. Phys Ther 2001;81:1192-205.

15. Ahmed RL, Schmitz KH, Prizment AE, Folsom AR. Risk factors for lymphedema in breast cancer survivors, the lowa Women's Health Study. Breast Cancer Res Treat 2011;30:981-91. [CrossRef]

16. Hosmer DW, Lemeshow S. Model Building Strategies and Methods. In: Editors Hosmer DW, Lemeshow S, eds. Applied Logistic Regression 2nd edition. New York, PA: Wiley, 2000, 95. [CrossRef]

17. Armer JM, Stewart BR. Post-breast cancer lymphedema: incidence increases from 12 to 30 to 60 months. Lymphology 2010;43:118-27.

18. Celebioglu F, Perbeck L, Frisell J, Gröndal E, Svensson L, Danielsson R. Lymph drainage studied by lymphoscintigraphy in the arms after sentinel node biopsy compared with axillary lymph node dissection following conservative breast cancer surgery. Acta Radiol 2007;48:488-95. [CrossRef]

19. Petrek JA, Hulan MC. Incidence of breast carcinoma related lymphedema. Cancer 1998;83:2776-81. [CrossRef]

20. McLaughlin SA, Wright MJ, Morris KT, Giron GL, Sampson MR, Brockway JP, et al. Prevalence of lymphedema in women with breast cancer 5 years after sentinel lymph node biopsy or axillary dissection: objective measurements. J Clin Oncol 2008;26:5213-9. [CrossRef]

21. Goldberg JI, Wiechmann LI, Riedel ER, Morrow M, Van Zee KJ. Morbidity of sentinel node biopsy in breast cancer: the relationship between the number of excised lymph nodes and lymphedema. Ann Surg Oncol 2010;17:3278-86. [CrossRef]

22. Kwan ML, Darbinian ], Schmitz KH , Citron R, Partee P, Kutner SE, et al. Risk factors for lymphedema in a prospective breast cancer survivorship study: the Pathways Study. Arch Surg 2010;145:1055-63. [CrossRef]

23. Mak SS, Yeo W, Lee YM, Mo KF, Tse KY, Tse SM, et al. Predictors of lymphedema in patients with breast cancer undergoing axillary 
lymph node dissection in Hong Kong. Nurs Res 2008;57:416-25. [CrossRef]

24. Fisher B, Anderson S, Redmond CK, Wolmark N, Wickerham DL, Cronin WM. Reanalysis and results after 12 years of follow-up in a randomized clinical trial comparing total mastectomy with lumpectomy with or without irradiation in the treatment of breast cancer. N Engl J Med 1995;333:1456-61. [CrossRef]

25. Brismar B, Ljungdahl I. Postoperative lymphoedema after treatment of breast cancer. Acta Chir Scand 1983;149:687-9.

26. Ray GR, Fish VJ, Marmor JB, Rogoway W, Kushlan P, Arnold C, et al. Impact of adjuvant chemotherapy on cosmesis and complications in stages I and II carcinoma of the breast treated by biopsy and radiation therapy. Int J Radiat Oncol Biol Phys 1984;10:837-41. [CrossRef]

27. Norman SA, Localio AR, Kallan MJ, Weber AL, Torpey HA, Potashnik SL, et al. Risk factors for lymphedema after breast cancer treatment. Cancer Epidemiol Biomarkers Prev 2010;19:2734-46. [CrossRef]

28. Specht MC, Miller CL, Russell TA, Horick N, Skolny MN, O'Toole JA, et al. Defining a threshold for intervention in breast cancer-related lymphedema: what level of arm volume increase predicts progression? Breast Cancer Res Treat 2013;140:485-94. [CrossRef]

29. Kiel KD, Rademacker AW. Early stage breast cancer: arm, edema after wide excision and breast irradiation. Radiology 1996;198:279-83. [CrossRef]

30. Koçak Z, Overgaard J. Risk factors of arm lymphedema in breast cancer patients. Acta Oncologica 2000;39:389-92. [CrossRef]

31. Marcks P. Lymphedema; pathogenesis, prevention, treatment. Cancer Pract 1997;5:32-8.

32. Werner RS, McCormick B, Petrek J, Cox L, Cirrincione C, Gray JR, et al. Arm edema in conservatively managed breast cancer: obesity is a major. Radiology 1991;180:177-84. [CrossRef]

33. Meeske KA, Sullivan-Halley J, Smith AW, McTiernan A, Baumgartner $K B$, Harlan LC, et al. Risk factors for arm lymphedema following breast cancer diagnosis in black women and white women. Breast Cancer Res Treat 2009;113:383-91. [CrossRef]

34. Petrek JA, Senie RT, Peters M, Rosen PP. Lymphedema in a cohort of breast carcinoma survivors 20 years after diagnosis. Cancer 2001;92:1368-77. [CrossRef]

35. Shaw C, Mortimer P, Judd PA. A randomized controlled trial of weight reduction as a treatment for breast cancer-related lymphedema. Cancer 2007;110:1868-74. [CrossRef]

36. Johansson K, Tibe K, Weibull A, Newton RC. Low intensity exercise for breast cancer patients with arm lymphedema with or without compression sleeve. Lymphology 2005;38:167-80.

37. Nielsen I, Gordon S, Selby A. Breast cancer-related lymphoedema risk reduction advice: a challenge for health professionals. Cancer Treat Rev 2008;34:621-8. [CrossRef]

38. Markowski J, Wilcox JP, Helm PA. Lymphedema incidence after specific postmastectomy therapy. Arch Phys Med Rehabil 1981;62:449-52.

39. Bohler FK, Rhomberg W, Doringer W. Hypertension as risk factor for increased rate of side effects in the framework of breast carcinoma irradiation. Strahlenther Onkol 1992;168:344-9.

40. Geller BM, Vacek PM, O'Brien P, Secker-Walker RH. Factors associated with arm swelling after breast cancer surgery. J Womens Health (Larchmt) 2003;12:921-30. [CrossRef]

41. Brennan MJ, Weitz J. Lymphedema thirty years after radical mastectomy. Am J Phys Med Rehabil 1992;71:12-4. [CrossRef]

42. Bentzen SM, Overgaard M, Thames HD Fractionation sensitivity of a functional endpoint: impaired shoulder movement after postmastectomy radiotherapy. Int J Radiat Oncol Biol Phys 1989;17:531-7. [CrossRef]

43. Armer JM, Radina ME, Porock D, Culbertson SD. Predicting breast cancer-related lymphedema using self-reported symptoms. Nurs Res 2003;52:370-9. [CrossRef] 